\title{
Competition between ruminal cellulolytic bacteria for adhesion to cellulose
}

\author{
P Mosoni, G Fonty, Ph Gouet \\ INRA, Laboratoire de Microbiologie, C.R. de Clermont-Ferrand-Theix \\ 63122 Saint Genès-Champanelle, France
}

Competition for growth were observed between the main ruminal cellulolytic bacterial species on cellulose and plant cell-walls (Odenyo et al, 1994, Appl Env Microbiol, 60, 3697-3703) but little is known about the origin of these competitions. Competition for adhesion sites on the cellulosic substrate could be the basic mechanism of these interactions. A competitive adhesion study was therefore undertaken by means of a differential radiolabeling of the bacterial species.

Ruminococcus flavefaciens FD1, Fibrobacter succinogenes $\mathrm{S} 85$ and Ruminococcus albus 20 were ${ }^{14} \mathrm{C}$ radiolabeled by growing cells to late log phase on modified medium 10 (Caldwell and Bryant, 1966, Appl Microbiol, 14, 794-801) with sodium $\left(2-{ }^{14} \mathrm{C}\right)$ acetate or sodium $\left(1{ }^{-14} \mathrm{C}\right)$ isobutyrate $(370$ $\mathrm{kBq} / \mathrm{ml}$ ). Cell titration was performed with sodium $\left({ }^{3} \mathrm{H}\right)$ acetate $\left(370 \mathrm{kBq} \cdot \mathrm{ml}^{-1}\right)$. Bacteria were anaerobically harvested, washed and resuspended as described by Morris and Cole (1987, J Gen Microbiol, 133, 1023-1032). The labeled cell suspension $(5 \mathrm{ml}$; O.D. $600 \mathrm{~nm}=$ $1 \pm 0.1$ ) was gently shaken with $50 \mathrm{mg}$ of microcrystalline cellulose Sigmacell 20 for 45 $\min$ at $39^{\circ} \mathrm{C}$. In these conditions, adhesion sites were limited for the three species. The cellulose was sedimented (500 g, $1 \mathrm{~min}$ ) and after removing the supernatant, washed with mineral buffer. The percentage of bound and free cells was determined by measuring the radioactivity in the cellulose pellet and supernatants respectively. To obtain a measure of adhesion competition between two species (one labeled with ${ }^{14} \mathrm{C}$, the other labeled with ${ }^{3} \mathrm{H}$ ), the percentage of adhering cells of each species in coculture was compared with the percentage obtained in the respective monoculture. The two species were incubated with cellulose either simultaneously or sequentially.

On average, the percentages of adherent bacteria in monoculture were $68 \pm 15 \%$ for $R$. flavefaciens FD1, $75 \pm 9 \%$ for $R$. albus 20 and $49 \pm 18 \%$ for $F$. succinogenes S85. The adhesion of $R$. flavefaciens FD1 was strongly inhibited ( $53 \%$ on average) by the adhesion of R. albus 20 , even when FD1 was first in contact with cellulose for $45 \mathrm{~min}$. In that coculture, $R$. albus 20 adhered as in monoculture. Adhesion of $F$. succinogenes $\mathrm{S} 85$ was inhibited ( $55 \%$ on average) when 585 and 20 were simultaneously added to cellulose, but no competition between the two strains was observed when $\mathrm{S} 85$ was already adherent. When $R$. flavefaciens FD1 and $F$. succinogenes $\mathrm{S} 85$ were introduced simultaneously, the adhesion of both species was slightly decreased (average of 7,5 and $16,5 \%$ respectively) but was not modified in the sequential assays whatever the order of inoculation.

These results underline different mechanisms of adhesion (differences in affinity for cellulose and adhesion sites) of the three strains but explain partly the competitions observed between these three species on cellulose. 